\title{
Indicadores em Nível de Sistema para Avaliar o Desenvolvimento e a Qualidade da Educação Superior Brasileira
}

\author{
Júlio C. G. Bertolin ${ }^{1}$
}

Recebido em: 21/05/07

Aprovado em: 25/05/07

Resumo: Este artigo propõe um sistema de indicadores para avaliar o desenvolvimento e a qualidade da educação superior brasileira em nível de sistema. Inicialmente, são abordados aspectos conceituais da qualidade em ES e é apresentado um entendimento de qualidade em nível de SES. Logo após são apresentados alguns dos principais sistemas de indicadores internacionais de avaliação de SES, tais como os da Unesco e da OCDE. Por fim, considerando-se as especificidades brasileiras, se desenvolve uma proposta de sistema de indicadores com aspectos de entradas, processo e resultados para avaliar o desenvolvimento e a qualidade da educação superior brasileira em nível de sistema.

Palavras-chave: Educação superior, avaliação de sistema, qualidade em educação superior, avaliação da qualidade em educação superior, sistema de indicadores de SES.

System-Level Indicators to Evaluate the Development and Quality of Brazilian Higher Education

Abstract: This article suggests a system of indicators to evaluate the development and the quality of Brazilian higher education in system-level. Initially, conceptual aspects of quality in higher education are discussed and an understanding of higher education quality in system-level is presented. In addition, some of the main international system-level indicators for higher education evaluation are presented, such as those set by Unesco and the OECD. Finally, considering Brazilian particularities, a proposal of an indicator system to evaluate the development and the quality of Brazilian higher education in system-level is made, with aspects relative to entrances, process and results.

Key-words: Higher education; evaluation system; quality in higher education; quality evaluation in higher education; system-level indicators for higher education.

\section{Introdução}

Nos últimos tempos os sistemas de indicadores têm sido um dos instrumentos mais importantes e utilizados em âmbito mundial para estudar e analisar o desenvolvimento, o desempenho e a qualidade dos sis-

1 Dr. em Educação pela Universidade Federal do Rio Grande do Sul (UFRGS), Prof. da Universidade de Passo Fundo (UPF), foi membro da Comissão Especial de Avaliação (CEA) do MEC, que elaborou a proposta original do Sinaes.E-mail: julio@upf.br 
temas nacionais de educação. Alguns dos mais importantes organismos internacionais e diversos países têm desenvolvido, elaborado e aplicado sistemas de indicadores com vistas a avaliar sistemas de educação.

Segundo diversos autores, a avaliação da qualidade em educação se expressa como um juízo de valor sobre um conjunto de atributos acerca das entradas, processo e resultados educativos, ou das relações entre eles. Essa definição envolve os elementos principais de um sistema e considera qualidade em educação como um conceito múltiplo que não pode ser avaliado por apenas um indicador. Tais sistemas de indicadores procuram superar a obtenção de uma simples soma de dados ao agrupar indicadores simples ou compostos em função de fatores e aspectos que lhes dêem sentido e uma visão significativa do estado dos sistemas de educação. Além disso, a teoria dos sistemas observa que o resultado do todo é maior do que a simples soma dos elementos ou das partes, ou seja, parece ser insuficiente avaliar um sistema de educação pela abordagem dos seus elementos (IES, cursos etc.) de forma individualizada, ou seja, um sistema não deve ser avaliado pela simples soma de suas partes, mas, sim, de forma global. Portanto, o desenvolvimento de um sistema de indicadores especificado segundo a visão sistêmica parece ser uma das mais adequadas estratégias para a realização de avaliações e medições do desenvolvimento e da qualidade de sistemas nacionais de educação superior.

O Brasil ainda não possui um sistema de indicadores estruturado em aspectos de entradas, processo e resultados para avaliar e acompanhar o desenvolvimento e a qualidade da educação superior brasileira em nível de sistema. Dessa forma, com base nos sistemas internacionais da Unesco e OCDE e na especificidade brasileira, o presente artigo propõe um sistema de indicadores para avaliar a qualidade da educação superior brasileira.

\section{Qualidade de um sistema de educação superior}

Nas décadas de 1960 e 1970 deu-se o auge das soluções quantitativas para a educação, as quais se expressaram em muitos países no aumento nos gastos com educação, no aumento do número de anos de ensino obrigatório, na diminuição da idade de ingresso na escola e no desenvolvimento de teses econômicas sobre a educação, como a "teoria do capital humano". No início da década de 1980 começaram a surgir os primeiros questionamentos acerca da qualidade em educação e já no final da mesma década o assunto se tornara uma prioridade nos EUA e na Europa. Assim, em virtude da crescente importância que a educação su- 
perior vem assumindo para o crescimento dos indivíduos e para o desenvolvimento sociocultural e econômico dos países e sociedades, a avaliação da qualidade dos sistemas e instituições educacionais tornou-se assunto de grande importância não apenas para governos e instituições, mas também para todas as sociedades. Atualmente, uma das palavras mais empregadas nos trabalhos e pesquisas no campo da educação superior é o termo "qualidade".

Diversas definições de qualidade começaram a surgir durante a década de 1980. Em 1983, Groot afirmou que a qualidade é determinada pelo grau em que um conjunto prévio de objetivos são satisfeitos; em 1985, C. Ball definiu qualidade como ajuste ao propósito e, pouco depois, qualidade foi discutida em termos da noção de valor agregado por T. Barnett, em 1988, e J. C. McClain, D. W. Krueger e T. Taylor, em 1989 (WATTY, 2005). Durante a década de 1990 surgiram as principais propostas de categorizações das diversas maneiras de se pensar a qualidade em ES. No ano de 1993, Lee Harvey e Diana Green publicaram, provavelmente, a mais conhecida das propostas de classificação de qualidade em ES na revista Assessment \& Evaluation in Higher Education. No artigo intitulado "Defining Quality" os autores compilaram a ampla diversidade de concepções existentes em cinco grupos distintos: qualidade como fenômeno excepcional, qualidade como perfeição ou coerência, qualidade como ajuste a um propósito, qualidade como relação custobenefício e qualidade como transformação.

Desde as propostas de taxionomias de qualidade em ES publicadas durante a década de 1990, como as de Barnett (1992), Harvey e Green (1993) e Green (1994) (falta ref.), a literatura especializada não apresenta novidades significativas sobre estudos de classificações e de conceitos sobre o assunto. Não obstante, nos últimos anos tem-se observado a emergência de novos termos para explicar as propriedades da qualidade em ES. Tal fato se deve, provavelmente, ao desenvolvimento de pesquisas segundo novas perspectivas e ao envolvimento de uma maior diversidade de stakeholders e organismos internacionais com os assuntos avaliação, medição e garantia da qualidade em educação.

Nesse contexto de desenvolvimento e novidades acerca da qualidade em ES, um mesmo termo pode adquirir diferentes sentidos para diferentes visões e, por outro lado, um mesmo significado pode possuir diferentes termos para denominá-lo. Entretanto, tais termos parecem surgir sempre vinculados com duas das principais idéias sobre as missões da educação superior neste início de século: (a) competitividade econômica e crescimento dos mercados e (b) desenvolvimento sociocultural e eco- 
nômico sustentável; ou, ainda, a uma visão de educação superior com missão primordial de (c) coesão social e equidade. Tal vinculação entre concepção de educação e visões de qualidade parece dar razão à premissa de Robert Barnett (1992) de que não é possível formar opinião consistente sobre qualidade em ES sem antes se ter uma razoável concepção da própria educação superior. De acordo com a premissa de Barnett e a partir da literatura recente e das publicações dos organismos internacionais, podem-se agrupar em três diferentes tendências de visão de qualidade em ES os termos sobre qualidade mais utilizados em âmbito mundial: visão economicista, visão pluralista e visão de eqüidade. (Figura 1)

\begin{tabular}{|l|l|l|l|}
\hline Visão de qualidade & Termos associados & Grupos de interesse & Propósitos da ES \\
\hline Visão economicista & $\begin{array}{l}\text { Empregabilidade e } \\
\text { Eficiência }\end{array}$ & $\begin{array}{l}\text { Setor privado, OCDE } \\
\text { e setor governamental }\end{array}$ & $\begin{array}{l}\text { Ênfase nos aspectos } \\
\text { de potencialização do } \\
\text { crescimento da } \\
\text { economia e da } \\
\text { empregabilidade }\end{array}$ \\
\hline Visão pluralista & $\begin{array}{l}\text { Diferenciação, } \\
\text { Pertinênciae } \\
\text { Relevância }\end{array}$ & $\begin{array}{l}\text { Unesco, União } \\
\text { Européia e setor } \\
\text { educativo }\end{array}$ & $\begin{array}{l}\text { Diversidade de } \\
\text { aspectos relevantes } \\
\text { (economia, } \\
\text { sociocultural, } \\
\text { democracia etc.) com } \\
\text { ênfase na emergência } \\
\text { das especificidades } \\
\text { locais }\end{array}$ \\
\hline Visão de eqüidade & Eqüidade & $\begin{array}{l}\text { Ênfase nos aspectos } \\
\text { de contribuição para } \\
\text { coesão social }\end{array}$ \\
\hline
\end{tabular}

Fonte: Bertolin, 2007.

Figura 1 - Visões de qualidade em educação superior

Ainda no início da década de 1990, Vroeijenstijn (1991) dizia que "é uma perda de tempo tentar definir qualidade", baseando-se no argumento de que se trata de um conceito relativo e que diferentes stakeholders em educação superior têm diferentes prioridades, com focos de atenção provavelmente diferenciados. De fato, é vasta na literatura das duas últimas décadas a afirmação de que qualidade em educação e, especificamente, em educação superior não possui um único significado. Portanto, a conclusão que estudos acerca de qualidade em ES tendem a chegar é que existem diversos, diferentes e legítimos entendimentos 
para o termo. Independentemente do nível de análise, o entendimento de qualidade em ES sempre pode variar no tempo e no espaço. É perfeitamente possível que a qualidade em ES tenha um significado para um grupo e, ao mesmo tempo, tenha outros, bem distintos, para outros grupos. O fato é que o entendimento de qualidade é inexoravelmente subjetivo, porque depende fundamentalmente das concepções de mundo e de educação superior de quem o emite.

Quando a análise da qualidade em ES se restringe ao âmbito dos sistemas de educação superior existem algumas abordagens específicas. Segundo Antonio Fazendeiro (2002, p. 64), numa abordagem da avaliação da qualidade nos planos macro (resultados e desempenhos do sistema) e mega (relevância dos resultados para a sociedade), a educação, para ser de qualidade, precisa reunir os atributos desejáveis e observáveis nas dimensões eqüidade, relevância e eficiência. Segundo o autor, eqüidade refere-se "às condições de igualdade de oportunidades no acesso e sucesso educativos por parte de todos e de cada um. Igualdade na diversidade e na coesão social"; a relevância refere-se à "qualidade nos resultados, socialmente relevantes, face às necessidades e às expectativas dos indivíduos e da sociedade em todas as suas dimensões, econômica, social ou cultural", e a eficiência e a eficácia na gestão dos recursos implicam "excelência da governação".

Para Mercedes G. García (2000, p. 240), a qualidade de um sistema de educação poderia ser definida e controlada desde quatro dimensões interdependentes: (i) qualidade como relevância: que asseguraria correspondência entre o que os estudantes aprendem e os requisitos sociais e individuais, ou seja, a avaliação estaria centrada na coerência entre as necessidades sociais e logros; (ii) qualidade como eficácia: que asseguraria que os estudantes aprendam efetivamente o que foi previamente definido nos planos de estudo e dentro do tempo estabelecido; dessa forma, a avaliação estaria centrada na correspondência entre os resultados logrados e os fins formulados; (iii) qualidade como eficiência: que asseguraria que os meios, estratégias e recursos utilizados permitam aumentar o nível tecnológico e econômico do país; assim, a avaliação estaria centrada na racionalização dos custos e na relação entre recursos empregados, processos utilizados e os resultados; (iv) qualidade como eqüidade: que asseguraria que todos os estudantes, independentemente de origem e condição social, familiar ou social, obtenham igualdade de oportunidades, desenvolvimento e resultados, ou seja, a avaliação centrar-seia na homogeneidade de resultados em todas as zonas geográficas do país. 
Segundo Fernanda Correia, Alberto Amaral e António Magalhães, em virtude da transformação dos SES de sistemas de elite para sistemas de massas, a diversificação dos sistemas ganhou uma significativa importância na administração e desenvolvimento dos sistemas e instituições, "sendo a diversificação considerada, na generalidade dos casos, como extremamente positiva" (2000, p. 5). Dentre os principais argumentos para justificar a importância da diversidade nos sistemas de educação superior estão $(i)$ a diversidade torna a educação superior mais acessível e aumenta a mobilidade social, (ii) a diversidade amplia as opções de escolha e responde às necessidades dos alunos, (iii) a diversidade responde melhor às pressões da sociedade e às necessidades do mercado de trabalho e (iv) a diversidade possibilita experiências novas de baixo custo em paralelo com a manutenção de instituições de elite.

Portanto, parece evidente que um sistema de educação superior, para ser considerado de qualidade, precisa, em primeiro lugar, possuir "relevantes" propósitos socioculturais e econômicos para o desenvolvimento e crescimento do seu país; em segundo lugar, por causa das inquestionáveis vantagens da presença de diferentes tipos de instituições e formação, parece claro que na atualidade, para um sistema de educação superior ser considerado de qualidade faz-se necessária a existência de "diversidade". Considerando-se, ainda, o contexto de uma nação, com seus valores democráticos de liberdade, solidariedade e justiça social, parece óbvio que um sistema de educação superior, para ser considerado de qualidade, também precisa proporcionar "igualdade de oportunidades" para todos os estudantes. Por fim, levando-se em conta que um sistema de educação precisa cumprir suas funções consideradas básicas de ensino e formação integral dos indivíduos e da sociedade, é evidente que deve ser "eficaz" na consecução desse objetivo.

Portanto, não obstante a existência de diferentes visões e concepções, a qualidade de um sistema de educação superior poderia ser adequadamente entendida como a existência das propriedades: $(i)$ de "relevância" para o desenvolvimento das mais diversas áreas socioculturais e econômicas do país; (ii) de "diversidade" para atender as mais diferentes demandas e necessidades de educação e formação; (iii) de "eqüidade" de oportunidade para todas as pessoas das mais diversas regiões e classes sociais do país; (iv) de "eficácia" na consecução de todas as funções básicas do SES e da formação integral dos indivíduos e da sociedade. 


\section{Sistemas de indicadores de avaliação de SES}

Em publicação de 1966, Y. C. Cheng (apud SAHNEY; BANWET; KARUNES, 2004) definiu qualidade educacional como "as características de um conjunto de elementos na entrada, processo, e saída do sistema educacional que proporcionam serviços que satisfazem completamente estratégias dos envolvidos internos e externos, contemplando suas implícitas e explícitas expectativas". Essa definição envolve as características de entradas, processo e resultados e múltiplos interessados em educação superior e considera qualidade em educação como um conceito múltiplo que não pode ser avaliado por apenas um indicador. Da mesma forma, para León R. G. Estrada (1999), a avaliação da qualidade em educação se "expressa como um juízo de valor sobre um atributo ou um conjunto de atributos acerca dos insumos [ou entradas], processos, resultados ou produtos educativos, ou das relações entre eles".

Alguns dos mais importantes organismos internacionais têm baseado avaliações, medições e acompanhamentos do desempenho dos sistemas nacionais de educação por meio de sistemas de indicadores, que também consideram aspectos de entradas e/ou recursos, processo e saídas e/ou resultados. Dentre outros, destacam-se os sistemas de indicadores desenvolvidos pela UNESCO, Comissão Européia e pela OCDE. (Figura 2)

\begin{tabular}{|c|c|}
\hline \multirow[t]{2}{*}{ The Broader Context } & 15 Changes in expenditure per student \\
\hline & 16 Cumulative expenditure per student \\
\hline 1 Total population & 17 Expenditure on educational institutions as percentage of GDP \\
\hline 2 Population growth rates & 18 Public subsidies in higher education \\
\hline 3 Ageing societies & 19 Research and development in higher education \\
\hline 4 Broadband connections & 20 Higher education R\&D financed by industry \\
\hline 5 Gross domestic product per capita & \\
\hline 6 Labour productivity & The Returns on Higher Education \\
\hline Acess, Participation Proaression & 21 Education and earnings \\
\hline Acess, rarticipalion, rrogression & 22 Differences in earnings between females and males \\
\hline & 23 Private internal rate of return of higher education \\
\hline 7 Educational attainment & 24 Education and work status (25-to-29-year-olds) \\
\hline 8 Number of science graduates & 25 Situation of the youth population with low levels of education \\
\hline $\begin{array}{ll}9 & \text { Survival rates in university-level education } \\
10 & \text { Students with disabilities in higher education }\end{array}$ & $\begin{array}{l}26 \text { Participation in continuing education and training (25-to-64 } \\
\text { year-olds) }\end{array}$ \\
\hline 11 Higher education R\&D expenditure by field of study & \\
\hline 12 Higher education researchers & Internationalisation of Higher Education \\
\hline 13 Women researchers & \\
\hline & 27 Foreign students in higher education \\
\hline Expenditure on Higher Education & $\begin{array}{l}28 \text { Foreign students in higher education by country of destination } \\
29 \text { Migration of the highly educated }\end{array}$ \\
\hline 14 Expenditure per student & 30 Foreign scholars in the United States \\
\hline
\end{tabular}

Fonte: OECD, 2006.

Figura 2 - Indicadores de SES do encontro de ministros da OCDE de 2006 
Mais recentemente, um número crescente de países também tem organizado sistemas de indicadores e publicações de avaliação dos seus sistemas de educação, dentre os quais se incluem Bélgica, Canadá, Dinamarca, Espanha, EUA, Finlândia, França, Holanda, Luxemburgo e Reino Unido. (NAVARRA, 2004). O entendimento conceitual do Laboratorio Latinoamericano de Evaluación de la calidad de la educación da Unesco $(1997$, p. 7) acerca do significado da qualidade tem "estreita relação com o nível de logro dos objetivos educacionais, no marco dos programas oficiais de estudo, levando em conta as variáveis de insumo [ou entradas] e especialmente processo". O conceito subjacente do órgão determina que:

o nível de qualidade da educação consiste basicamente na definição de um conjunto de variáveis que proporcione, em forma sistemática, um quadro confiável e válido acerca do estado dos sistemas de educação e que pode ser utilizado para colaborar na orientação e ações de melhoria (UNESCO, 1997, p.7)

De acordo com Mercedes G. Garcia (2000), os sistemas de indicadores procuram superar a obtenção de uma simples soma de dados ao agrupar indicadores simples ou compostos em função de fatores e aspectos que lhes dêem sentido e uma visão significativa do estado dos sistemas de educação. Portanto, pode-se dizer, com segurança, que os recentes modelos conceituais e operacionais elaborados com vistas a avaliar, medir e monitorar o desenvolvimento e a qualidade dos sistemas de educação têm se baseado em estruturas sistêmicas de indicadores que consideram aspectos de (i) entradas e/ou recursos, de (ii) processo e de (iii) resultados e/ou de saídas ${ }^{2}$.

Geralmente, os indicadores de entradas referem-se aos recursos, tanto financeiros como humanos e tecnológicos, que se destinam à educação. Aspectos relativos aos gastos com educação, investimento com tecnologia de informações e quantidade e formação dos docentes também podem estar incluídos entre os indicadores de entrada e/ou recursos. Os indicadores de processo referem-se ao contexto pedagógico e organizacional, ou seja, dizem respeito às características primárias, relativas à participação direta do processo de educação, e secundárias, relativas ao apoio à organização das características primárias. Aspectos relativos ao número de horas de ensino, número de horas, salário e dedicação dos docentes, e acesso e uti-

2 Existe certa variedade de denominações para representar os indicadores relacionados aos propósitos dos sistemas de educação, tais como, "produtos", "resultados" ou "saídas" dos sistemas. Neste estudo é adotado, predominantemente, a denominação de "indicadores de resultados" para todos os aspectos relativos aos mais diversos propósitos de um sistema de educação. 
lização das TIC podem compor a estrutura dos indicadores de processo. Os indicadores de resultados referem-se às características relativas aos propósitos intermediários e últimos da educação; nível de êxito dos alunos em exames nas diversas disciplinas, proporção de diplomados e taxas de escolarização e impactos no desenvolvimento econômico e social podem estar entre os indicadores de resultados. (ESTRADA, 1999; EUROPEAN COMISSION, 2001; OECD, 2002; NAVARRA, 2004).

Dessa forma, não obstante a existência e possibilidade de outras formas de organização, os sistemas de indicadores proposto para avaliar e medir o desenvolvimento e a qualidade dos SES geralmente possuem estruturas sistêmicas com elementos de entradas, processo e resultados. (Figura 3)

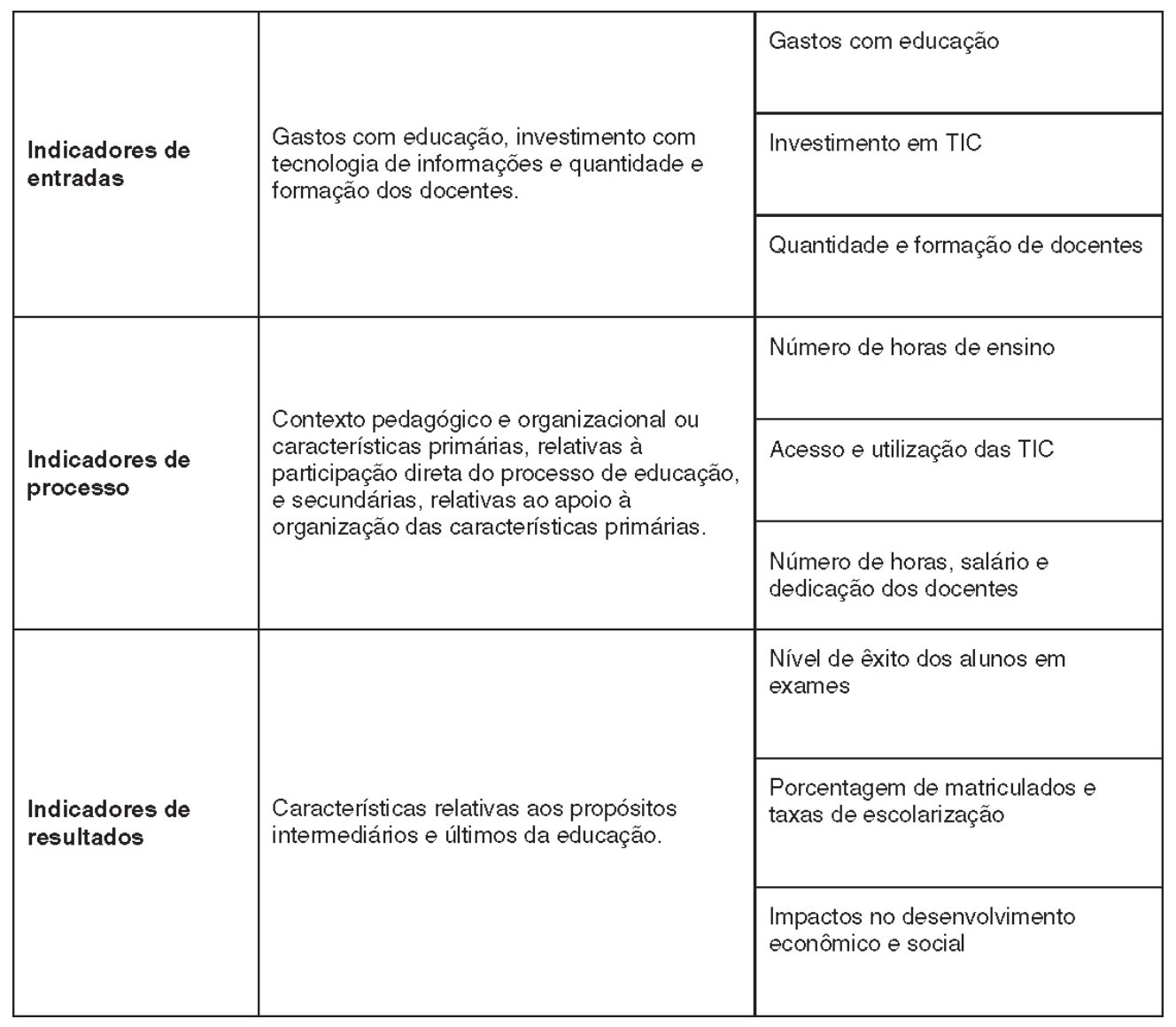

Fonte: Bertolin, 2007.

Figura 3 - Estrutura básica do sistema de indicadores para SES. 
Ainda não existe um consenso geral sobre a quantidade necessária, tampouco sobre os aspectos mais apropriados para comporem um sistema de indicadores de SES, porém pode-se dizer que existem alguns aspectos presentes na maioria dos instrumentos desenvolvidos nos países e pelos organismos internacionais. Não obstante os sistemas de indicadores terem se desenvolvido nos últimos dez anos, segundo muitos especialistas, ainda há muito a ser feito para a qualificação e aperfeiçoamento de tais instrumentos.

\section{Um sistema de indicadores para avaliar a qualidade do Sesb}

No Brasil, o principal órgão responsável pelos estudos e estatísticas da educação superior é o Inep - Instituto Nacional de Estudos e Pesquisas Educacionais "Anísio Teixeira". Estudos recentes demonstraram que as informações disponibilizadas pelo Inep são insuficientes para a avaliação e acompanhamento da qualidade do sistema de educação superior brasileiro - Sesb ${ }^{3}$ (BERTOLIN, 2007). Não obstante possuir relevantes dados, o Censo da Educação Superior, que se baseia em informações repassadas pelas instituições ao Inep, não permite uma medição e avaliação do Sesb de forma sistêmica completa. Diversas e importantes informações, como, por exemplo, taxas de empregabilidade dos egressos, nível de internacionalização do sistema, investimento e tempo de ensino relativo às TIC, financiamento privado detalhado por organização acadêmica, entre outros, não são encontradas nas bases de dados do Inep para períodos recentes. Portanto, a avaliação do desenvolvimento e da qualidade do SES por meio de um sistema de indicadores ainda não é realizada no Brasil.

Dessa forma, o presente trabalho elabora um sistema de indicadores para avaliar o desenvolvimento e a qualidade da educação superior brasileira em nível de sistema. Para cumprir tal tarefa, o modelo se baseia ( $i$ ) no conceito de qualidade em ES apresentado nesse trabalho: eficácia, diversidade, relevância e eqüidade; (ii) no modelo de indicadores sistêmico estruturado em aspectos de entradas, processo e resultados; (iii) nos indicadores e aspectos de avaliação de SES propostos pelos organismos internacionais Unesco-Cepes, OCDE e BM; (iv) nos aspectos socioculturais e econômicos do Brasil contemporâneo para melhor avaliar a relevância do Sesb.

\footnotetext{
3 Do ponto de vista legal, não existe um sistema nacional de educação superior brasileiro único. No presente trabalho, a sigla Sesb (SES brasileiro) será utilizada num sentido amplo para referir-se à existência de órgãos estatais de regulação e avaliação da educação superior e de IES postos a operar conjuntamente a partir dos marcos legais e das políticas em curso.
} 
A seguir, os sistemas de indicadores e aspectos considerados pela Unesco-Cepes, OCDE e BM serão analisados individualmente em relação as suas características ( $i$ ) de tipo de abordagem sistêmica (entradas, processo e resultados), (ii) de vinculação com as propriedades de qualidade de SES apontadas nesse trabalho - eficácia, relevância, eqüidade e diversidade -, e (iii) de possíveis formas de mensuração (indicadores quantitativos). Com base nessa análise, então, são extraídos indicadores e aspectos aplicáveis e adequados ao conceito e entendimento de qualidade de um SES com vistas à construção do sistema de indicadores para o Sesb.

\section{Referência dos Indicadores da Unesco-Cepes}

O projeto Strategic Indicators for Higher Education in the TwentyFirst Century, coordenado pelo European Centre for Higher Education da Unesco, Bucareste, Romênia, procura estabelecer um sistema de indicadores estratégicos para monitorar o nível de desenvolvimento dos sistemas de educação superior dos países membros da entidade. O projeto está relacionado com os dois documentos que resultaram da Conferência Mundial da Educação Superior ocorrida em Paris em 1998: "Higher education in the twenty-first century: vision and action" e o "Framework for priority action for change and development of higher education". Assim, o sistema de indicadores proposto pela Unesco-Cepes busca contribuir com as reflexões acerca do desenvolvimento da educação superior de acordo com o contexto da visão postulada durante o encontro de Paris. A estrutura da proposta está baseada em quatro conjuntos de aspectos sobre um sistema de educação superior: indicadores do quadro referencial das políticas; indicadores de financiamento; indicadores dos níveis de participação, acesso e retenção e indicadores de resultados econômicos e sociais (UNESCO, 2003). A Figura 4 estabelece a relação de alguns dos principais indicadores propostos pelo projeto da Unesco com o conceito de qualidade de um SES adorado nesse trabalho e com a estrutura sistêmica de indicadores com vistas a apontar indicadores para compor o sistema de avaliação e medição da qualidade do Sesb.

Dessa forma, com vistas à elaboração de um sistema de indicadores para a qualidade do Sesb, os indicadores da Unesco-Cepes a seguir descritos serão tomados como referência: taxa de docentes com doutorado, gastos em P\&D na ES, investimento da iniciativa privada em P\&D na ES, gastos com educação superior público e privado como porcentagem 


\begin{tabular}{|c|c|c|}
\hline Sistema UNESCO-CEPES & Indicadores propostos & $\begin{array}{l}\text { priedades de } \\
\text { alidade }\end{array}$ \\
\hline \multicolumn{3}{|c|}{ A) Indicadores de quadro referencial que suporta as políticas e os desenhos de políticas } \\
\hline \multicolumn{3}{|l|}{$\begin{array}{l}\text { 1.1 Quadro das políticas de prestação de contas e } \\
\text { tomada de decisão: nacional e institucional }\end{array}$} \\
\hline Envolvimento de todos os stakeholders relevantes & \multirow[t]{4}{*}{-} & \multirow[t]{4}{*}{-} \\
\hline $\begin{array}{l}\text { Participação e envolvimento das mulheres na } \\
\text { tomada de decisão }\end{array}$ & & \\
\hline $\begin{array}{l}\text { Envolvimento dos estudantes em decisões políticas } \\
\text { [institucionais] }\end{array}$ & & \\
\hline $\begin{array}{l}\text { Alta qualidade de avaliação [institucional] interma e } \\
\text { extema }\end{array}$ & & \\
\hline \multicolumn{3}{|l|}{$\begin{array}{l}1.2 \text { Políticas claras para o pessoal acadêmico da } \\
\text { educação superior }\end{array}$} \\
\hline $\begin{array}{l}\text { Políticas claras relativas aos professores da } \\
\text { educação superior }\end{array}$ & \multirow{2}{*}{$\begin{array}{l}\text { (i) Tempo de dedicação dos } \\
\text { docentes ao ensino e a pesquisa-P; } \\
\text { (ii) Taxa de docentes com } \\
\text { doutorado-E. }\end{array}$} & \multirow{2}{*}{$\begin{array}{l}\text { Indicadores de entradas } \\
\text { e processo relacionados } \\
\text { com a propriedade de } \\
\text { eficácia do sistema. }\end{array}$} \\
\hline $\begin{array}{l}\text { Participação [de todo pessoal acadêmico] em ensino } \\
\text { e pesquisa }\end{array}$ & & \\
\hline \multicolumn{3}{|l|}{ 1.3 Promoção e desenvolvimento de pesquisa } \\
\hline $\begin{array}{l}\text { Reforço da ligação entre educação superior e } \\
\text { pesquisa }\end{array}$ & \multirow{3}{*}{$\begin{array}{l}\text { (iii) Gastos em P\&D na ES-E; (iv) } \\
\text { Taxa de docentes envolvidos com } \\
\text { pesquisa-P; (V) Taxa de discentes } \\
\text { envonvidos com pesquisa-R; (vi) } \\
\text { Investimento da iniciativa privada } \\
\text { em P\&D na ES-E. }\end{array}$} & \multirow{3}{*}{$\begin{array}{l}\text { Indicadores de } \\
\text { entradas, processo e } \\
\text { resultados relacionados } \\
\text { com as propriedades de } \\
\text { eficácia e relevância do } \\
\text { sistema. }\end{array}$} \\
\hline $\begin{array}{l}\text { Proximidade entre educação superior e instituições } \\
\text { de pesquisa }\end{array}$ & & \\
\hline $\begin{array}{l}\text { Desenvolvimento de pesquisa em todas as } \\
\text { disciplinas da educação superior }\end{array}$ & & \\
\hline \multicolumn{3}{|l|}{$\begin{array}{l}\text { 1.4 Condições de liberdade e autonomia } \\
\text { (institucional, acadêmica e estudantil) }\end{array}$} \\
\hline \multicolumn{3}{|l|}{ B) Indicadores de financiamento } \\
\hline \multicolumn{3}{|l|}{ 2.1 Financiamento realizado na educação superior } \\
\hline $\begin{array}{l}\text { Empenho de recursos humanos, materiais e } \\
\text { financeiros }\end{array}$ & $\begin{array}{l}\text { (vii) Gastos com educação superior } \\
\text { público e privado como } \\
\text { porcentagem do PIB-E; (viii) Gastos } \\
\text { com ensino como porcentagem do } \\
\text { gasto total com ES-E. }\end{array}$ & Indicadores de entrada. \\
\hline \multicolumn{3}{|l|}{2.2 Incremento de colaboração com outros países } \\
\hline $\begin{array}{l}\text { Cooperação crescente entre todos os países em } \\
\text { todos os níveis do desenvolvimento econômico }\end{array}$ & \multirow[t]{2}{*}{ - } & \multirow[t]{2}{*}{ - } \\
\hline $\begin{array}{l}\text { Redução da distância existente entre as nações } \\
\text { industrialmente desenvolvidas e as em } \\
\text { desenvolvimento }\end{array}$ & & \\
\hline 2.3 Uso de novas tecnologias & & \\
\hline $\begin{array}{l}\text { Uso das TICs que estão se generalizando da forma } \\
\text { mais expansiva possível para ajudar as instituições } \\
\text { de educação superior }\end{array}$ & $\begin{array}{l}\text { (ix) Porcentagem do tempo que os } \\
\text { cursos de graduação utilizam TIC- } \\
\text { P. }\end{array}$ & $\begin{array}{l}\text { Indicador de processo } \\
\text { relacionado com a } \\
\text { propriedade de eficácia. }\end{array}$ \\
\hline
\end{tabular}


Indicadores em Nível de Sistema para Avaliar o

Desenvolvimento e a Qualidade da Educação Superior Brasileira

\begin{tabular}{|c|c|c|}
\hline \multicolumn{3}{|c|}{ C) Indicadores de níveis apropriados de participação, acesso e retenção } \\
\hline 3.1 Expansão do acesso & & \\
\hline [Quando necessário] diversificar e expandir o acesso & \multirow{3}{*}{$\begin{array}{l}\text { (x) Número total e por disciplina } \\
\text { de estudantes para cada grupo } \\
\text { de } 100 \text { mil hab.-R; (xi) } \\
\text { Porcentagem de discentes com } \\
25 \text { anos ou mais-R. }\end{array}$} & \multirow{3}{*}{$\begin{array}{l}\text { Indicadores de resultado } \\
\text { relacionados com a } \\
\text { propriedade de eficácia. }\end{array}$} \\
\hline $\begin{array}{l}\text { Altemativas e flexibilidade nos pontos de entrada e } \\
\text { saída }\end{array}$ & & \\
\hline Educação permanente e/ou continuada & & \\
\hline \multicolumn{3}{|l|}{ 3.2 Equidade no acesso } \\
\hline Acesso para todos com base no mérito & \multirow{3}{*}{$\begin{array}{l}\text { (xii) Razão entre a proporção de } \\
\text { estudantes da ES das classes } \\
\text { sociais mais baixas e a } \\
\text { proporção da população de } \\
\text { classes sociais mais baixas-R; } \\
\text { (xiii) Razão de homens para } \\
\text { mulheres entre os calouros-R; } \\
\text { (xiv) Porcentagem de mulheres } \\
\text { envolvidas em programas de } \\
\text { pesquisa em relação ao total de } \\
\text { estudantes pesquisadores-R; } \\
\text { (xv) Porcentagem de estudantes } \\
\text { que trabalham-R. }\end{array}$} & \multirow{3}{*}{$\begin{array}{l}\text { Indicadores de resultado } \\
\text { relacionados com a } \\
\text { propriedade de equidade do } \\
\text { sistema. }\end{array}$} \\
\hline Consolidação da participação das mulheres & & \\
\hline $\begin{array}{l}\text { Criação de entradas, especialmente para estudantes } \\
\text { mais velhos }\end{array}$ & & \\
\hline \multicolumn{3}{|l|}{ 3.3 Provisão de auxílio ao estudante } \\
\hline $\begin{array}{l}\text { Formas de auxílio aos estudantes, incluindo medidas } \\
\text { para melhorar condiçōes de vida dos estudantes }\end{array}$ & $\begin{array}{l}\text { (xvi) Taxa de retenção do } \\
\text { primeiro ano-R; (xvii) Razão } \\
\text { entre discentes e todos os } \\
\text { docentes-E; (xviii) Razão entre } \\
\text { discentes e pessoal-R. }\end{array}$ & $\begin{array}{l}\text { Indicadores de entradas e } \\
\text { resultados relacionados com } \\
\text { a propriedade de eficácia do } \\
\text { sistema. }\end{array}$ \\
\hline \multicolumn{3}{|l|}{ D) Indicadores de resultados econômicos e sociais } \\
\hline \multicolumn{3}{|l|}{$\begin{array}{l}\text { 4.1 Ligações entre educação superior, industria e } \\
\text { emprego de graduados }\end{array}$} \\
\hline $\begin{array}{l}\text { Ligações próximas entre educação superior e mundo } \\
\text { do trabalho }\end{array}$ & $\begin{array}{l}\text { (ixx) Taxa de emprego de } \\
\text { graduados: dois anos ou mais, } \\
\text { total e por disciplina-R. }\end{array}$ & $\begin{array}{l}\text { Indicador de resultados } \\
\text { relacionado a propriedade de } \\
\text { relevância do sistema. }\end{array}$ \\
\hline \multicolumn{3}{|l|}{ 4.2 Promoção da mobilidade intemacional } \\
\hline $\begin{array}{l}\text { Auxílio no desenvolvimento de mobilidade intemacional } \\
\text { e nacional do pessoal e dos estudantes }\end{array}$ & $\begin{array}{l}\text { (xx) Porcentagem de discentes } \\
\text { estrangeiros em relação a todos } \\
\text { os discentes-P; (xxi) } \\
\text { Porcentagem dos docentes com } \\
\text { mais alta titulação obtida no } \\
\text { exterior-E. }\end{array}$ & $\begin{array}{l}\text { Indicadores de entradas e } \\
\text { processo relacionados com } \\
\text { as propriedades de eficácia. }\end{array}$ \\
\hline \multicolumn{3}{|l|}{$\begin{array}{l}\text { 4.3 Efeitos catalisadores dos sistemas globais e locais } \\
\text { no desenvolvimento regional e nacional }\end{array}$} \\
\hline Estímulo para todo o sistema de educação & $\begin{array}{l}\text { (xxii) Taxas de participação da } \\
\text { Educação por nível-R. }\end{array}$ & $\begin{array}{l}\text { Indicador de resultados } \\
\text { relacionado com a } \\
\text { propriedade de relevância. }\end{array}$ \\
\hline
\end{tabular}

\section{Figura 4 - Sistema da Unesco-Cepes para indicadores de qualidade do Sesb}


do PIB, gastos com ensino como porcentagem do gasto total com ES, razão entre discentes e todos os docentes e porcentagem dos docentes com mais alta titulação obtida no exterior, como indicadores de entradas; tempo de dedicação dos docentes ao ensino e a pesquisa, taxa de docentes envolvidos com pesquisa, porcentagem do tempo que os cursos de graduação utilizam TIC e porcentagem de discentes estrangeiros em relação a todos os discentes, como indicadores de processo; taxa de discentes envonvidos com pesquisa, número total e por disciplina de estudantes para cada grupo de 100 mil habitantes, porcentagem de discentes com 25 anos ou mais, razão entre a proporção de estudantes da ES das classes sociais mais baixas e a proporção da população de classes sociais mais baixas, razão de homens para mulheres entre os calouros, porcentagem de mulheres envolvidas em programas de pesquisa em relação ao total de estudantes pesquisadores, porcentagem de estudantes que trabalham, taxa de retenção do primeiro ano, razão entre discentes e pessoal, taxa de emprego de graduados: dois anos ou mais, total e por disciplina e taxas de participação da educação por nível, como indicadores de resultados.

\section{Referência dos Indicadores da OCDE}

A OCDE também tem se ocupado com avaliação e medição de sistemas nacionais de educação. Na avaliação que a OCDE está desenvolvendo do sistema de educação superior de Portugal, por exemplo, o organismo busca descrever e apontar algumas análises acerca das tendências e problemas em termos de eqüidade, eficácia e eficiência. Aspectos relacionados à missão da educação superior, acesso e eqüidade, qualidade da oferta, recursos humanos, recursos financeiros e internacionalização são abordados pela OCDE com vistas ao desenvolvimento da avaliação do sistema global de educação superior (CIPES, 2006). A Figura 5 estabelece a relação dos aspectos considerados pela OCDE na avaliação de um SES com o conceito de qualidade de um SES adotado nesse trabalho, com a estrutura sistêmica de indicadores e aponta possíveis formas de mensuração de tal avaliação.

Dessa forma, com vistas à elaboração do sistema de indicadores para a qualidade do Sesb, os aspectos considerados pela OCDE a seguir descritos serão tomados como referência: gastos com educação superior público e privado por discente e gastos em pesquisa por tipo de instituição - inclusive com subsídios para o setor privado, como indicadores de entradas; porcentagem dos discentes por tipos de cursos, porcentagem dos cursos e 


\begin{tabular}{|c|c|c|}
\hline Avaliação da OCDE & Indicadores propostos & Propriedades de qualidade \\
\hline - Sistema de governo & - & - \\
\hline $\begin{array}{l}\text { - Participaçăo, por faixa-etária e por } \\
\text { tipos de cursos }\end{array}$ & $\begin{array}{l}\text { (xxiii) Porcentagem dos } \\
\text { discentes por faixas-etárias- } \\
\text { R; (xxiv) Porcentagem dos } \\
\text { discentes por tipos de } \\
\text { cursos-P. }\end{array}$ & $\begin{array}{l}\text { Indicadores de processo e } \\
\text { resultados relacionados com } \\
\text { as propriedades de eficácia e } \\
\text { diversidade do sistema. }\end{array}$ \\
\hline $\begin{array}{l}\text { - Despesas totais, no meio } \\
\text { governamental ou outros meios }\end{array}$ & $\begin{array}{l}\text { (xXV) Gastos com educaçăo } \\
\text { superior público e privado } \\
\text { por discente-E. }\end{array}$ & Indicador de entrada. \\
\hline - Despesas com pesquisas & $\begin{array}{l}\text { (xxvi) Gastos em pesquisa } \\
\text { por tipo de instituição - } \\
\text { inclusive com subsídios para } \\
\text { o setor privado-E. }\end{array}$ & $\begin{array}{l}\text { Indicador de entrada } \\
\text { relacionado a propriedade de } \\
\text { diversidade e relevância. }\end{array}$ \\
\hline - Custo médio por tipo de estudo & - & - \\
\hline - Gusto médio por indivíduos & - & - \\
\hline - Equidade no acesso & $\begin{array}{l}\text { (xxvii) Razão entre a } \\
\text { proporçăo de estudantes da } \\
\text { ES das regióes do país e a } \\
\text { proporção da população } \\
\text { dessas regiöes-R. }\end{array}$ & $\begin{array}{l}\text { Indicador de resultado } \\
\text { relacionado a propriedade de } \\
\text { equidade. }\end{array}$ \\
\hline - O sistema de garantia da qualidade & $\begin{array}{l}\text { (xxviii) Porcentagem dos } \\
\text { cursos e instituiçŏes } \\
\text { avaliadas-P. }\end{array}$ & $\begin{array}{l}\text { Indicador de processo } \\
\text { relacionado a propriedade de } \\
\text { eficácia. }\end{array}$ \\
\hline - Ligações com o sistema secundário & - & - \\
\hline - Ligações com o mercado de trabalho & - & - \\
\hline - Relacionamentos internacionais & $\begin{array}{l}\text { (ixxxx) Porcentagem de } \\
\text { discentes estudando no } \\
\text { estrangeiro em relação a } \\
\text { todos os discentes-P }\end{array}$ & $\begin{array}{l}\text { Indicador de processo } \\
\text { relacionado com a } \\
\text { propriedade de eficácia. }\end{array}$ \\
\hline
\end{tabular}

Fonte: Elaborado pelo autor a partir de CIPES, 2006.

\section{Figura 5 - Avaliação da OCDE para indicadores de qualidade do Sesb}

instituições avaliadas e porcentagem de discentes estudando no estrangeiro em relação a todos os discentes, como indicadores de processo; e porcentagem dos discentes por faixas-etárias e razão entre a proporção de estudantes da ES das regiões do país e a proporção da população dessas regiões, como indicadores de resultados. 


\section{Referência dos Indicadores do Banco Mundial}

Segundo textos do Banco Mundial, a instituição orienta reformas essenciais nas políticas com vistas a tornar os sistemas de educação superior mais eficientes, relevantes, eqüitativos, transparentes e responsivos. Segundo o próprio banco, ao dar suporte à implantação de reformas na educação superior, se priorizam programas e projetos que podem trazer desenvolvimento e inovações positivas para: $(i)$ incrementar a diversidade institucional; ( $i$ i) fortalecer a pesquisa científica e tecnológica e o desenvolvimento da educação; (iii) melhorar a qualidade e a relevância da educação terciária; (iv) promover grandes mecanismos de eqüidade para ajudar estudantes em desvantagem; $(v)$ estabelecer sistemas de financiamento sustentáveis para incentivar a responsabilização e flexibilidade; (vi) fortalecer as capacidades gerenciais; (vii) realçar e expandir a capacidade das TIC para reduzir a exclusão digital (WORLD BANK, 2006). A Figura 6 estabelece a relação dos aspectos e dados considerados pelo Banco Mundial na análise do desenvolvimento de um SES com o conceito de qualidade de um SES adotado nesse trabalho e com a estrutura sistêmica de indicadores.

Dessa forma, com vistas à elaboração do sistema de indicadores para a qualidade do Sesb, os aspectos considerados pelo Banco Mundial a seguir descritos serão tomados como referência: porcentagem de gastos com educação superior, como indicadores de entradas; e taxa de escolarização bruta feminina na educação superior, taxa de escolarização bruta na educação superior, porcentagem de diplomados em educação superior no conjunto da força de trabalho e porcentagem de mulheres com diplomada de educação terciária no conjunto da força de trabalho, como indicadores de resultados.

\section{Referência do contexto sociocultural e econômico brasileiro}

A elaboração do sistema de indicadores para o Sesb deve considerar, além dos indicadores avaliados pelos organismos internacionais (Unesco, OCDE e BM), questões e desafios contemporâneos específicos da sociedade brasileira e de seu SES. Como a concepção adotada por este trabalho busca adequar-se à visão pluralista de qualidade em ES, considerando de forma igual as contribuições do Sesb para o crescimento da economia e para o desenvolvimento sociocultural, da eqüidade e da coesão social, faz-se necessário uma breve identificação das grandes 


\begin{tabular}{|c|c|c|}
\hline Análise do Banco Mundial & Indicadores propostos & $\begin{array}{l}\text { Propriedades de } \\
\text { qualidade }\end{array}$ \\
\hline \multirow[t]{4}{*}{$\begin{array}{l}\text { - Governança } \\
\text { - Financiamento } \\
\text { - Garantia da qualidade } \\
\text { - Educação permanente (aprendizagem ao } \\
\text { longo da vida) } \\
\text { - Equidade }\end{array}$} & $\begin{array}{l}\text { [Gastos por discentes com } \\
\text { educação pública (\% per capita } \\
\text { do PIB)] } \\
\text { (xxx) Porcentagem de gastos } \\
\text { com educação superior - E (\% } \\
\text { total dos gastos) }\end{array}$ & $\begin{array}{l}\text { Indicadores de } \\
\text { entrada. }\end{array}$ \\
\hline & $\begin{array}{l}\text { [Docentes na educação } \\
\text { superior] } \\
\text { [Docentes do sexo femininos na } \\
\text { educaçăo superior] }\end{array}$ & $\begin{array}{l}\text { Indicadores de } \\
\text { processo. }\end{array}$ \\
\hline & $\begin{array}{l}\text { [Porcentagem de moças } \\
\text { (mulheres adultas) na } \\
\text { educação superior] } \\
\text { (xxxl) Taxa de escolarização } \\
\text { bruta feminina na educaçăo } \\
\text { superior-R; } \\
\text { [Taxa de escolarização bruta } \\
\text { masculina na educação } \\
\text { superior] }\end{array}$ & $\begin{array}{l}\text { Indicadores de } \\
\text { resultados } \\
\text { relacionados a } \\
\text { propriedade de } \\
\text { equidade. }\end{array}$ \\
\hline & $\begin{array}{l}\text { (xxxii) Taxa de escolarização } \\
\text { bruta na educação superior-R; } \\
\text { [Matriculas na educação } \\
\text { superior] } \\
\text { (xxxiii) Porcentagem de } \\
\text { diplomados em educação } \\
\text { superior no conjunto da força } \\
\text { de trabalho-R; } \\
\text { (xxxiv) Porcentagem de } \\
\text { mulheres com diploma de } \\
\text { educação terciária no conjunto } \\
\text { da força de trabalho-R; } \\
\text { [Porcentagem de homens com } \\
\text { diploma de educação superior } \\
\text { no conjunto da força de } \\
\text { trabalho] } \\
\text { [total da força de trabalho] }\end{array}$ & $\begin{array}{l}\text { Indicadores de } \\
\text { resultados } \\
\text { relacionados a } \\
\text { propriedade de } \\
\text { eficácia e equidade. }\end{array}$ \\
\hline
\end{tabular}

Fonte: Elaborado pelo autor a partir de WORLD BANK, 2006.

\section{Figura 6 - Análise do Banco Mundial para indicadores de qualidade do Sesb}

questões e problemas nacionais atuais nos mais diferentes aspectos. Dessa forma, a escolha de indicadores também terá origem em questões relativas ao contexto sociocultural e econômico específico do Brasil contemporâneo. Portanto, o sistema de indicadores proposto estará respeitando o princípio da "diferenciação", considerando o contexto do Sesb confor- 
me a especificidade da realidade brasileira, que em muitos casos difere dos contextos dos SES de outros países e desenvolvendo a avaliação da "relevância" do Sesb de forma mais eficaz, pois tratará das necessidades específicas do Brasil atual ${ }^{4}$.

O Brasil é um país com extensões territoriais quase continentais, possui uma ampla heterogeneidade regional em relação aos aspectos étnicos, geográficos, socioculturais e econômicos e, sem dúvida, trata-se de uma nação altamente complexa em todas as suas dimensões de Estado, sociedade civil e mercado. No entanto, a identificação das principais questões e problemas nacionais na atualidade não pode ser considerada uma tarefa muito complexa. Pode-se dizer inclusive, que nos mais variados fóruns de debate acadêmico, nas diferentes instâncias empresariais e dos trabalhadores, na arena política e nos próprios meios de comunicação, existe certo consenso acerca dos grandes problemas nacionais: $(i)$ desigualdade e exclusão social (concentração da riqueza nas mãos de poucos); ( $i i)$ crescimento econômico insuficiente (falta de infra-estrutura, carência de capital humano qualificado, necessidade de reformas estruturais - política, tributária, etc.); (iii) sistema educacional deficiente qualitativa e quantitativamente (resultados negativos nas avaliações internacionais na educação básica e baixa taxa de escolaridade na ES); (iv) dependência externa e atraso no âmbito científico-tecnológico; ( $v)$ graves problemas sociais de natureza ético-moral e de violência e insegurança.

Nesse contexto, o sistema de educação superior brasileiro, para poder ser considerada como pertinente e relevante para o país, deve considerar, no estabelecimento de suas funções, as grandes questões nacionais e atuar principalmente com vistas a fazer frente às iniqüidades existentes, às deficiências e problemas educacionais e procurar desenvolver a ciência e tecnologia com o objetivo de contribuir no desenvolvimento sociocultural, econômico e tecnológico do país. Dessa forma, a elaboração do sistema de indicadores para avaliar e medir o desenvolvimento da qualidade do Sesb, proposta por este trabalho contemplará tais especificidades do contexto brasileiro pela inclusão na estrutura básica do sistema de indicadores dos seguintes subgrupos: 'Investimento em

\footnotetext{
4 Não obstante a utilização de indicadores quantitativos, não se pode considerar que a proposta de sistema de indicadores para a qualidade do Sesb deste trabalho é baseada numa concepção de qualidade predominantemente economicista (isomorfismo, empregabilidade etc.) visto que se levam em conta, sobretudo, as especificidades do contexto brasileiro, aspectos de eqüidade, diversidade e relevância.
} 
pesquisa' no grupo dos indicadores de entradas; 'Diversificação de IES, cursos e áreas', 'Internacionalização dos discentes' e 'Avaliação de IES e cursos' no grupo de indicadores de processo; 'Equidade social e regional' no grupo dos indicadores de resultados.

\begin{tabular}{|c|c|c|}
\hline \multirow{4}{*}{ Entradas } & $\begin{array}{l}\text { A-Investimento em } \\
\text { educação }\end{array}$ & $\begin{array}{l}\text { A1. Porcentagem de investimento estatal e privado em ES em } \\
\text { relação ao PIB } \\
\text { A2. Porcentagem de investimento estatal em ES em relaçăo ao } \\
\text { total investido em educação } \\
\text { A3. Investimento com educação superior por discente: geral, estatal } \\
\text { e privado }\end{array}$ \\
\hline & $\begin{array}{l}\text { B-Investimento em } \\
\text { pesquisa }\end{array}$ & $\begin{array}{l}\text { B1. Investimento em P\&D na ES: geral, estatal e privado } \\
\text { B2. Investimento estatal em P\&D por tipo de instituição (estatal, } \\
\text { privada, universidades, não-universidade, tecnológica) }\end{array}$ \\
\hline & $\begin{array}{l}\text { C-Investimento em } \\
\mathrm{TIC}\end{array}$ & C1. Investimento em TICs para a ES: geral, estatal e privado \\
\hline & $\begin{array}{l}\text { D-Quantidade e } \\
\text { formaçăo docente }\end{array}$ & $\begin{array}{l}\text { D1. Razão entre discentes e docentes com alta titulação } \\
\text { D2. Razão entre discentes e todos os docentes } \\
\text { D3. Porcentagem de docentes com mais alta titulaçäo obtida no } \\
\text { exterior }\end{array}$ \\
\hline \multirow{6}{*}{ Processo } & $\begin{array}{l}\text { E-Número de horas } \\
\text { de ensino }\end{array}$ & $\begin{array}{l}\text { E1. Número da carga horária média dos cursos de graduação } \\
\text { E2. Porcentagem de tempo dos docentes dedicados a P\&D }\end{array}$ \\
\hline & $\begin{array}{l}\text { F-Acesso e utilização } \\
\text { das TIC }\end{array}$ & $\begin{array}{l}\text { F1. Porcentagem de tempo de ensino em que os cursos de } \\
\text { graduação utilizam TIC }\end{array}$ \\
\hline & $\begin{array}{l}\text { G-Número de horas, } \\
\text { salário e } \\
\text { dedicação dos } \\
\text { docentes }\end{array}$ & $\begin{array}{l}\text { G1. Taxa média de dedicação de tempo dos docentes para ES } \\
\text { G2. Média salarial dos docentes da ES: geral, estatal e privada } \\
\text { G3. Taxa de rotatividade de docentes nas instituiçóes }\end{array}$ \\
\hline & $\begin{array}{l}\text { H-Diversificação de } \\
\text { IES, cursos e áreas }\end{array}$ & $\begin{array}{l}\text { H1. Porcentagem dos discentes por tipos de cursos de graduação } \\
\text { (presencial, a distância, licenciaturas, tecnológicos, bacharelados) } \\
\text { H2. Porcentagem dos discentes por grandes áreas do } \\
\text { conhecimento }\end{array}$ \\
\hline & $\begin{array}{l}\text { I-Internacionalização } \\
\text { dos discentes }\end{array}$ & $\begin{array}{l}\text { 11. Porcentagem de discentes estrangeiros em relação a todos os } \\
\text { discentes } \\
\text { 12. Porcentagem de discentes estudando no estrangeiro em relação } \\
\text { a todos os discentes }\end{array}$ \\
\hline & $\begin{array}{l}\text { J-Avaliaçăo de IESe } \\
\text { cursos }\end{array}$ & J1. Porcentagem dos cursos e instituições avaliadas externamente \\
\hline
\end{tabular}




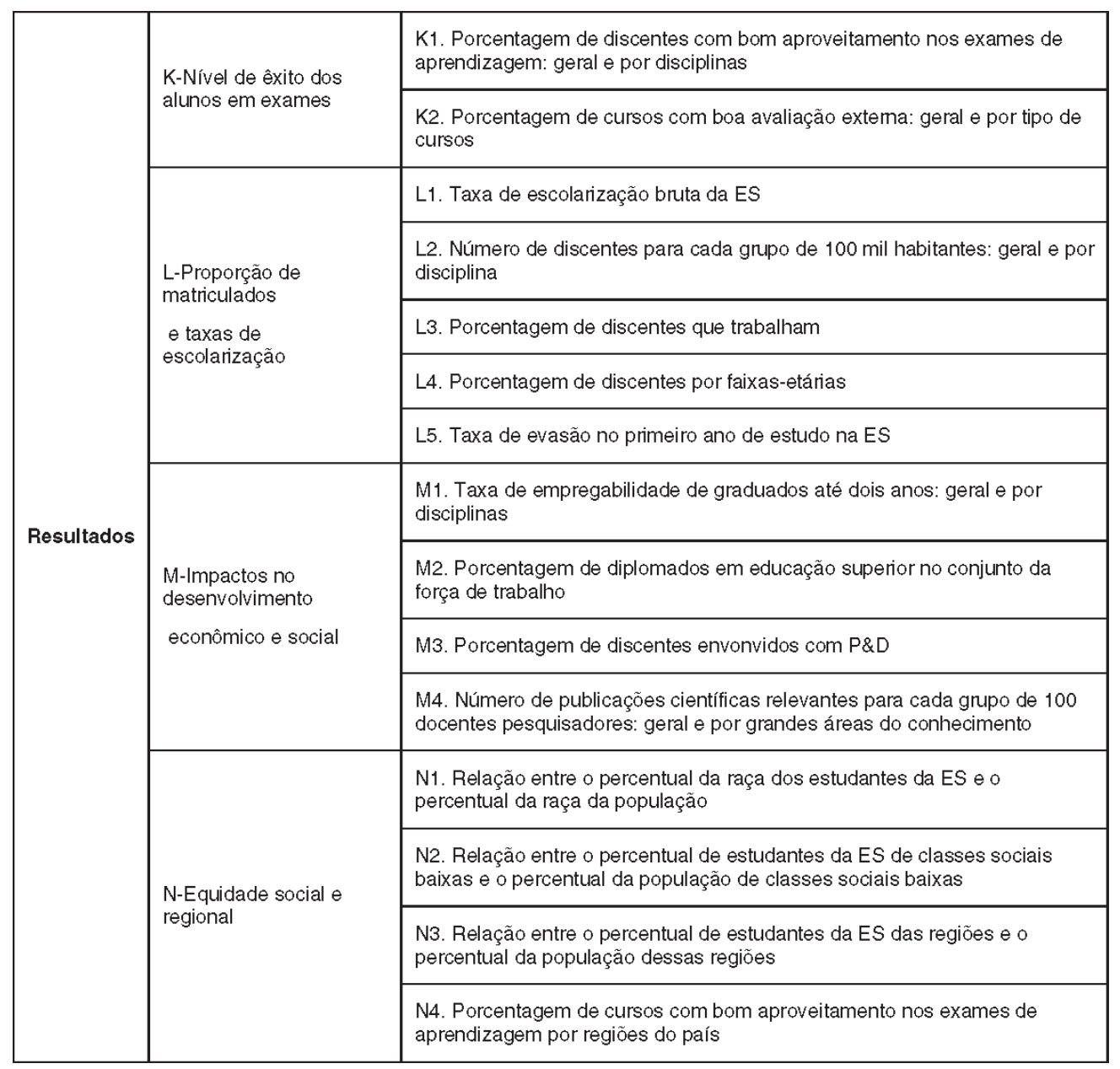

Fonte: Elaborado por Julio C. G. Bertolin, 2007.

Figura 7 - Sistema de Indicadores para a qualidade do Sesb

Finalmente, para concluir a elaboração do sistema de indicadores para o Sesb, foram incluídos indicadores relacionados com a estrutura sistêmica e que não estavam presentes nos modelos dos organismos internacionais: no subgrupo 'Número de horas, salário e dedicação dos docentes', foram anexados os indicadores 'Taxa média de dedicação de tempo dos docentes para ES' e 'Média salarial dos docentes da ES: geral, estatal e privada'; no subgrupo 'Diversificação de IES, cursos e áreas', foi inserido o indicador 'Porcentagem dos discentes por grandes áreas do conhecimento'; no 
subgrupo 'Nível de êxito dos alunos em exames', foram anexados os indicadores 'Porcentagem de discentes com bom aproveitamento nos exames de aprendizagem: geral e por disciplinas (Provão e Enade)' e 'Porcentagem de cursos com boa avaliação externa: geral e por tipo de cursos'; e no subgrupo, 'Impactos no desenvolvimento econômico e social', foi inserido o indicador 'Número de publicações científicas relevantes para cada grupo de 100 docentes pesquisadores: geral e por grandes áreas do conhecimento'.

Assim, após a observância e embasamento em conceito de qualidade em ES, em modelo de sistema de indicadores, nos indicadores dos organismos internacionais e nos aspectos socioculturais e econômicos do Brasil, chegou-se ao sistema de indicadores representado na Figura 7, com vistas a avaliar o desenvolvimento e a qualidade da educação superior brasileira em nível de sistema.

\section{Conclusão}

O sistema de indicadores elaborado neste trabalho, muito provavelmente, é a primeira proposta de indicadores sistêmicos para avaliar de forma global o desenvolvimento e a qualidade da educação superior brasileira em nível de sistema. Assim como diversos países desenvolvidos e reconhecidos organismos internacionais, o Brasil necessita adotar um sistema de indicadores estruturado em aspectos de entradas, processo e resultados para avaliar de forma mais ampla seu sistema de educação superior. Entretanto, não deve importar sistemas prontos, mas sim adaptar e ajustar modelos reconhecidos a sua realidade e especificidade.

Assim, o presente trabalho, com base ( $i$ ) no conceito de qualidade em ES entendido como as propriedades de eficácia, diversidade, relevância e eqüidade; (ii) no modelo de sistema de indicadores sistêmico estruturado em aspectos de entradas, processo e resultados; (iii) nos indicadores e aspectos de avaliação de SES propostos pelos organismos internacionais Unesco-Cespes, OCDE e BM; (iv) nos aspectos socioculturais e econômicos do Brasil contemporâneo para melhor avaliar a relevância do Sesb, desenvolveu uma proposta de sistema de indicadores global e sistêmico para avaliar o desenvolvimento e a qualidade da educação superior brasileira em nível de sistema. 


\section{REFERÊNCIAS}

BARNETT, Ronald. Improving higher education: total quality care. Bristol, USA: SRHE and Open University Press, 1992.

BERTOLIN, Julio C. G. Avaliação da qualidade do sistema de educação superior brasileiro em tempos de mercantilização período 1994-2003. 2007. Tese (Doutorado em Educação) Universidade Federal do Rio Grande do Sul, Porto Alegre, 2007.

CENTRO DE INVESTIGAÇÃO DE POLÍTICAS DO ENSINO SUPERIOR - CIPES. Outline of the Background Report for Portugal's Tertiary sector - OCDE. Matosinhos, Portugal: CIPES, 2006. Documento com Esboço do Relatório Base da Avaliação da OCDE do Sistema de Educação Superior de Portugal.

CORREIA, F.; AMARAL, A.; MAGALHÃES, A. Diversificação e diversidade dos sistemas de ensino superior: o caso português. Matozinhos, Portugal: CIPES, 2000.

ESTRADA, León R. G. Hacia un modelo de evaluación de la calidad de instituciones de educación superior. Revista Iberoamericana de Educación, Local, n. 21, dez. 1999. Universidad siglo XXI, OEI Ediciones, Dez. 1999.

EUROPEAN COMISSION. European report on quality of school education. Sixteen quality indicators. Brussels: 2001.

FAZENDEIRO, Antonio. Avaliação da qualidade da educação: uma abordagem no quadro do planejamento. In: CNE. Qualidade e avaliação da educação. Lisboa: CNE - Ministério da Educação, Jul. 2002. Seminários e Colóquios

GARCÍA, Mercedes G. Evaluación y calidad de los sistemas educativos . In: RAMÍREZ, Teresa G. (Org.). Evaluación y gestión de la calidad educativa. Málaga: Ediciones Aljibe, 2000.

GREEN, Diana. What is quality in higher education? Bristol: SRHE and Open University Press, 1994.

HARVEY, Lee; GREEN, Diana. Defining quality. Assessment \& Evaluation in Higher Education, v. 18, n.1, p. 9-26, Apr. 1993.

NAVARRA. Sistema de indicadores de la educación de Navarra 2003. Navarra: Gobierno de Navarra, 2004. 
ORGANISATION ECONOMIC CO-OPERATION AND

DEVELOPMENT -OECD. Education at a glance: OECD indicators 2002. Paris, 2002.

ORGANISATION ECONOMIC CO-OPERATION AND

DEVELOPMENT -OECD. Higher education: quality, equity and efficiency. Athens, 2006.

SAHNEY, S.; BANWET, D. K.; KARUNES S. Conceptualizing total quality management in higher education. The TQM Magazine, v. 16, $\mathrm{n}$. 2, p. 145-159, 2004.

UNESCO. Marco conceptual. Documentos - Laboratorio

Latinoamericano de evaluación de la calidad de la educación. Santiago, Chile: Lecce, Orealc/Unesco, 1997.

UNESCO. System-level and strategic indicators for monitoring higher education in the twenty-first century. Studies on higher education. Bucharest: CEPES, 2003.

VROEIJENSTIJN, T. I. External quality assessment: servant of two masters? In: CONFERENCE ON QUALITY ASSURANCE IN HIGHER EDUCATION, 1991, Hong Kong. Hong Kong: HKCAA, 1991.

WATTY, Kim. Quality in accounting education: what say the academics? Quality Assurance in Education, Melbourne, Austrália, v. 13, n. 2, p. 120-131, 2005.

WORLD BANK. Tertiary Education. Disponível em: <http:// web.worldbank.org/WBSITE/EXTERNAL/TOPICS/ EXTEDUCATION0,,contentMDK:20298183 menuPK:617592 pagePK:148956 piPK:216618 theSitePK:282386,00.html>. Acesso em: 13 ago. 2006. 